\title{
Antagonismo de classes no canto II da Ilíada: Tersites e a economia da guerra
}

\section{Sérgio Luiz Gusmão Gimenes Romero}

As guerras mentem. Nenhuma guerra tem a honestidade de confessar: "eu mato para roubar". A guerra sempre invoca nobres motivos...

Eduardo Galeano, Class antagonism in Iliad book II: Thersites and the economy of war.

Resumo: Este artigo apresenta uma reflexão crítica acerca do canto II da llíada, especificamente os versos 198 a 226, centrados na personagem Tersites. Esse trecho é alvo de polêmica teórica acerca de tratar-se o conflito entre o referido soldado e os chefes da armada como um embate entre classes sociais distintas. A partir de uma perspectiva materialista histórica, propomo-nos a defender uma abordagem do embate pelo viés de classe e de luta de classes sociais como cerne de sua dinâmica.

Palavras-chave: Tersites. Classe social. Guerra. Marxismo.

Abstract: This paper presents a critical reflection on the lliad book II, in particular verses 198-226, about the character of Thersites. This excerpt causes controversy because of the confrontation between the common soldier and the military commanders, the scene can be analyzed as an example of class conflict. From the historical-materialist perspective, the present study intends to defend the genuine position of the class struggle in this conflict.

Keywords: Thersites. Social class. Warfare. Marxism.

Resumen: Este artículo presenta una reflexión acerca del canto II de la llíada, especificamente los versos 198- 226, centrados en el personaje Tersites. Ese fragmento ha sido blanco de polémicas teóricas, pues se puede tratar el conflicto entre el soldado y los jefes de la armada como un enfrentamiento entre clases sociales distintas. A partir de una perspectiva del materialismo histórico, nos proponemos defender un abordaje del conflicto desde un punto de vista de clase y de lucha de clases sociales como centro de su dinámica.

Palabras clave: Tersites. Clase social. Guerra. Marxismo.

${ }^{1}$ Professor efetivo da Universidade do Estado de Minas Gerais (UEMG), no Campus de João Monlevade (MG). Mestre em Estudos Literários pela Faculdade de Ciências e Letras de Araraquara (UNESP). 
O episódio protagonizado por Tersites no canto II da Ilíada, versos 198 a 266, foi e continua sendo amplamente discutido, inclusive no que tange à sua interpretação enquanto um conflito entre classes sociais antagônicas: de um lado, teríamos Tersites, um integrante do plêthus - performatizando a vox populi; e, do outro, os representantes da elite guerreira formada pelos aristoi: Ulisses, Aquiles e Agamémnon, rei de reis. Partindo em maior ou menor grau, da teoria social iniciada por Karl Marx e Friedrich Engels ainda no século XIX, vários autores engajaram-se nessa leitura; tantos talvez quanto aqueles que se propuseram a refutá-la. A presente reflexão se alinha, expressamente, à primeira tendência, com o fito de lançar, quem sabe, alguma nova luz sobre o debate a partir de algumas considerações teóricas sobre a abordagem da passagem por um viés marxista.

Nesse sentido, faz-se necessário pontuar que a discussão aqui proposta versa especialmente sobre a formação social que se delineia no texto da llíada. Assim, não se abordarão aqui os detalhes das correspondências do épico para com diferentes conjunturas sócio-históricas que concretamente se desenvolveram na Antiguidade, sejam elas pertencentes à sociedade micênica ou à chamada Idade das Trevas. Afinal, a problemática dessas possíveis convergências exige um tratamento exclusivo haja vista sua complexidade. Como assinala Robin Osborne:

\footnotetext{
Bronze Age as well as early Iron Age archaeology can help us understand the resources out of which Homer's society is created. But the Homeric poems show an awareness of particular material circumstances not found before the later eighth or early seventh centuries (...). They also show a concern with social and political circumstances peculiarly apposite for eighth- and seventh-century Greeks as they began to assert community identities and devise, in part in connection with settlement abroad, rules for communal living (2006, p. 218).
}

No que tange à aplicabilidade da teoria sócio-histórica de Marx à Antiguidade, segundo Antônio Barros de Castro (1980, p. 74 apud CARDOSO, 1998, p. 178), o posicionamento teórico de Marx e Engels é taxativo no que diz respeito a que: "não apenas o capitalismo como também as sociedades précapitalistas deveriam ser estudadas a partir das condições materiais da vida". Não obstante, a aplicabilidade de algumas das principais categorias marxistas às idiossincrasias do mundo antigo está longe de ser consensual. 
No breve comentário aqui apresentado, adotamos teoricamente a hipótese de que, mutatis mutandis, tanto a categoria de "classe social", quanto a perspectiva metodológica do chamado materialismo histórico dialético ${ }^{2}$ se mostram viáveis e profícuas no que tange à análise da Antiguidade grega e, mais especificamente, do episódio da llíada que nos propomos a abordar.

Em relação à categoria marxista de "classe social" e à noção de luta de classes, obviamente, não integra esse breve comentário à perspectiva de uma discussão mais ampla e de uma problematização teórica pormenorizada de tais conceitos ou de sua aplicabilidade em sociedades pré-capitalistas, tais como a formação social representada em Homero. Não obstante, convém explicitar que nossa adoção metodológica desse referencial se baseia, entre outros, na fundamentação teórica e na discussão da operacionalidade de tais ferramentas de análise efetuada pelo historiador britânico marxista Geoffrey Ernest Maurice de Sainte Croix.

Nessa perspectiva, parece-nos interessante pontuar a proposição de identificar na própria guerra uma categoria que, na Antiguidade grega e, explicitamente, na sociedade homérica, integra estruturalmente o sistema de produção. De acordo com Sainte Croix:

(...) la primera tarea del hombre em la sociedad es la de organizar la
producción, en sentido lato, que incluye tanto la adquisición fuera de su
sociedad, por intercambio o por apropiación violenta, de las cosas
necesarias o deseadas que la sociedad requiere, pero que no puede
producir, o no puede hacerlo de modo provechoso, en su propio seno,
como la distribución de dicha producción. (...) por el mero hecho de vivir
en sociedade y organizar la producción, el hombre entra
necesariamente en un sistema determinado de relaciones sociales y
económicas, a las que Marx se refiere llamándolas "relaciones de
producción" o "relaciones sociales de producción" (SAINTE CROIX,
1988, p. 51).

Como o autor observa, a produção das condições de existência abrange a apropriação externa daquilo que não pode ser produzido autonomamente. Considerando as limitações das forças produtivas no contexto antigo, bem como

\footnotetext{
${ }^{2}$ Evidentemente, não se trata de adotar uma perspectiva fatorialista, comum ao marxismo vulgar, segundo a qual o fator econômico determinaria mecanicamente a realidade histórica e social, mas antes, de "representar a coisa na sua totalidade (e examinar ainda a ação recíproca dos seus diferentes aspectos). (MARX; ENGELS, 2007, p. 42). O próprio Engels já advertira que o determinismo economicista consistia leitura equivocada da teoria proposta por ele e por Marx. (Cf. PAULO NETTO, 2011, p. 13-4).
} 
as restrições no que diz respeito ao intercâmbio entre os oikos - circunscrito às trocas de dons e contradons ${ }^{3}$ - a "apropriação violenta" da atividade bélica assume um caráter fundamental na dinâmica das relações sociais de produção. Dessa forma, é possível interpretar as atividades militares de cerco, tomada de cidades e subsequente pilhagem, retratadas em Homero, como ações de caráter econômico em sentido amplo, ou seja, atividades inerentes ao modo de produção da formação social representada pela épica.

Parece-nos importante indicar, aqui, a posição de Thalmann, para quem: "The definitions by de Ste. Croix might apply to Homer, if only approximately (...). The difficulty is that we know too little about "modes of production" in Homeric society to apply such concepts systematically" (1988, p. 4). O autor aparentemente não considera o fato de que, para Sainte Croix, a própria guerra constitui parte fundamental do modo de produção. Ainda assim, Thalmann admite que: "I am not myself a Marxist, but I have made use of Marxist writers in this paper because I have found in them the most explicit and sustained discussion of these and related matters" (1988, p. 5).

Segundo Michel Austin e Vidal-Naquet, no que se refere à organização social, política e econômica "o papel essencial, no mundo homérico, é desempenhado pelo oikos aristocrático. Os grandes heróis ocupam o primeiro plano e agem habitualmente por conta própria, como se a comunidade não existisse" (1986, p. 50).

Interessante notar aqui que, em contraste com a indiferença para com a comunidade que, segundo os autores, a ação dos "grandes heróis" enseja, a fala de Tersites constrói-se, discursivamente, em torno de um "nós": "As tuas tendas estão cheias de bronze e muitas mulheres/ escolhidas estão nas tuas tendas, essas que nós Aqueus/ te demos em primeiro lugar, quando saqueávamos uma cidade" (v. 226-8).

Em relação ao oikos, ainda, os autores sublinham sua dimensão econômica e social:

\footnotetext{
3 "Encontramos na Odisseia (não na llíada) numerosos exemplos de uma técnica das trocas, a do dom e do contra-dom, que é bem conhecida em numerosas sociedades primitivas. No mundo homérico, como em numerosas sociedades arcaicas não existem dons desinteressados. Não se dá simplesmente para ser agradável, mas porque se antecipa a curto ou longo prazo, um presente ou um serviço em retribuição. O princípio é de tal modo admitido no mundo homérico que nunca é posto em questão: é uma prática que o poeta subentende como óbvia. $\mathrm{O}$ dom funda a obrigação do contradom (AUSTIN; VIDAL-NAQUET, 1986, p. 53).
} 
O oikos engloba os bens de toda a espécie, móveis e imóveis, inseparáveis na prática do agrupamento humano, visto que são eles que asseguram a sua existência material. Fazem parte do oikos, por conseguinte, as terras, as edificações, o gado, as reservas de todo o tipo, o material, etc. O oikos é uma unidade econômica ao mesmo tempo que uma unidade humana, e é regido pelo chefe do oikos, que será no mundo homérico um grande chefe guerreiro, como Menelau ou Ulisses. Do ponto de vista econômico, o ideal econômico é a autarcia (...): o oikos deve, tanto quanto possível, bastar-se a si próprio (...) (AUSTIN; VIDAL-NAQUET, 1986, p. 51).

E, em consonância com Sainte Croix, realçam a dimensão econômica da guerra:

Entre as comodidades essenciais que o oikos não podia fornecer estavam sobretudo os metais e os escravos: era impossível permanecer sem contacto com o mundo exterior. (...)

O primeiro meio de aquisição é muito simplesmente a guerra e, em Homero, sobretudo na llíada, é claro, a guerra aparece mais franca e brutalmente do que na história grega posterior (1986, p. 52).

A partir do exposto, é possível admitir a dimensão econômica do conflito bélico retratado parcialmente na llíada. O estabelecimento dessa questão constitui, de fato, um primeiro passo em nossa abordagem do confronto entre Tersites e os chefes aqueus, Agamémnon, Aquiles e Ulisses, em sentido lato, como um conflito de classes sociais.

A definição que Sainte Croix propõe da categoria de "classe social", e que aqui adotamos, fundamenta-se no estabelecimento da dimensão econômica, e da questão da exploração especificamente, como princípio norteador essencial, em detrimento da dimensão política da configuração de classes e de seus antagonismos. Assim:

Una clase (fundamentalmente una relación) es la expresión social colectiva del hecho de la explotación, la manera en la que se encarna la explotación en una estructura social. Y por explotación entiendo la apropriación de parte del producto del trabajo ajeno: en una sociedad productora de bienes de consumo es la apropiación de lo que Marx llamaba "plusvalía".

Una clase (uma clase en particular) es un grupo de personas de una comunidad que se identifica por su posición en el sistema global de producción social, definida ante todo con arreglo a sus relaciones (basicamente según el grado de posesión o control de ellas que tengan) con las condiciones de producción (es decir, los medios y el trabajo de producción) y con otras clases (SAINTE CROIX, 1988, p. 60). 
Dessarte, a articulação política de determinado grupo social não constitui condição sine qua non para falarmos de classes e de luta de classes; antes, este antagonismo decorre forçosamente da dinâmica de exploração que se constitui pela apropriação do excedente da produção de um agrupamento economicamente objetivado pelo outro.

Evidentemente, a adesão a essa perspectiva não implica uma rejeição às especificidades tácitas da configuração das classes sociais e da luta de classes nas formações sociais capitalistas e pré-capitalistas. Essas idiossincrasias já foram objeto de reflexão não só do próprio Marx, mas de eminentes representantes do materialismo histórico, como Lucáks ${ }^{4}$ e Hobsbawm. Assim, nas palavras deste último: "Class in the full sense only comes into existence at the historical moment when classes being to acquire consciousness of themselves as such" (1971, p. 6).

E ainda:

In other words, under capitalism class is an immediate and in some sense a directly experienced historical reality, whereas in pre-capitalist epochs it may merely be na analytical construct which makes sense of a complex of facts otherwise inexplicable (HOBSBAWM, 1971, p. 8).

Como se pode notar, a aplicabilidade da noção de classes ao contexto pré-capitalista é entendida por Hobsbawm de maneira ligeiramente distinta da concepção de Sainte Croix: para aquele, as particularidades de contextos anteriores à formação do capitalismo, mais propriamente a ausência de uma consciência de classe em termos objetivos, dificultaria o emprego pleno dessa categoria marxista nesse gênero de formação social. Não obstante, a perspectiva adotada por Hobsbawm não é completamente incompatível com a de Sainte Croix $^{5}$, ao menos nesse ponto específico. De fato, é possível estabelecer certa convergência uma vez que nos parece acertado considerar que a noção de

\footnotetext{
${ }^{4}$ Os interesses de classe na sociedade pré-capitalista nunca conseguem se distinguir claramente no que concerne ao aspecto econômico. A divisão da sociedade em castas, em estamentos etc, implica que, na estrutura econômica objetiva da sociedade, os elementos econômicos se unem inextricavelmente aos elementos políticos, religiosos etc (...).

A diferença muito surpreendente que mais nos importa agora é que toda sociedade pré-capitalista forma uma unidade incomparavelmente menos coerente, do ponto de vista econômico, do que a capitalista (LUCÁKS, 2003, p. 148-9).

${ }^{5}$ O próprio Sainte Croix admite isso: cf. 1988, p. 82.
} 
classe "em sentido pleno" se justapõe especificamente à realidade capitalista; isso não implica, todavia, a obliteração de sua aplicabilidade, em sentido lato, às formações econômicas pré-capitalistas.

A questão consiste em que, na perspectiva ora adotada, a categoria de classe social, em sua aplicação ao contexto das relações representadas na Ilíada, decorre objetivamente de uma dinâmica socioeconômica, prescindindo em maior ou menor grau da dimensão política da consciência da classe explorada acerca de sua própria exploração. Desse modo, consideramos que as ações de Tersites constituem-se reativa e instintivamente frente à opressão materialmente percebida, sem que disso decorra uma elaboração política verdadeiramente consciente da condição de opressão.

Ainda no tocante à categoria de classe aplicada a Homero, as considerações de Thalmann nos soam sobremaneira adequadas:

\begin{abstract}
I take it as legitimate to speak of a division between the common people (themselves probably with several sub-groups such as peasants and arti- sans) and above them either kings (basileis) or, more likely, a king and an aristocracy. This distinction is the essential point for our purposes, and we shall be concerned here with one aspect of the relation between these groups: the dominance of one over the other (1988, p. 4).
\end{abstract}

É evidente que, a despeito da focalização aqui adotada, outros elementos podem ser tomados como indícios para que se especule sobre uma distinção de classe na llíada, não necessariamente derivados apenas do modo de produção. Assim:

Membership in an illustrious genos carries with it not only a heavy obligation to preserve its good name, but also considerable advantage at birth. Aside from the material benefits of residence and inheritance rights, noble ancestry confers the automatic status that comes with the family name (DONLAN, 2007, p. 37).

Podemos considerar até detalhes aparentemente mais singelos: "Both major heroes and the mass of the army are heavily armed (...). Only major champions, however, travel about the battlefield in chariots." (OSBORNE, 2006, 
p. 215). Ou mesmo outras cenas da llíada que se mostram fundamentais para essa discussão, como o discurso de Sarpédon a Glauco (XII, v. 310-328) ${ }^{6}$.

Com efeito, a posição marxiana a respeito da análise das sociedades antigas em termos de antagonismos de classe é bastante conhecida: "A história de todas as sociedades até hoje existentes é a história das lutas de classes." (MARX; ENGELS, 2005, p. 40) ${ }^{7}$. A célebre formulação do Manifesto expressa uma noção basilar do pensamento de Marx, retomada em diversos outros textos - a luta de classes como força motriz da história.

Uma passagem interessante de outro autor clássico do marxismo parece produtiva para a presente discussão:

\begin{abstract}
E que são as classes em geral? São aquilo que permite a uma parte da sociedade apropriar-se do trabalho da outra. Se uma parte da sociedade se apropria de toda a terra, temos as classes dos latifundiários e dos camponeses. Se uma parte da sociedade tem as fábricas, tem as acções e os capitais, enquanto a outra trabalha nessas fábricas, temos as classes dos capitalistas e dos proletários (LENIN, 1980, p. 392).
\end{abstract}

De maneira simples, porém funcional, Lenin elabora o conceito de classe a partir da relação de apropriação do produto do trabalho de um grupo social por outro. Será que, a partir desse esboço, não poderíamos também pensar a relação que necessariamente se estabelece na llíada entre a massa de soldados mobilizados para a tomada de Tróia e a elite proprietária das naus que os conduzem a ílion, condição imprescindível para que a guerra aconteça? As possibilidades de leitura assentadas em uma perspectiva marxista são amplas.

Uma vez realizados os apontamentos necessários no que concerne à questão teórico-metodológica, parece-nos possível enunciar, em termos objetivos, nossa hipótese de leitura da passagem aqui analisada. Ela consiste em uma compreensão da guerra enquanto atividade de caráter econômico, ou seja, como parte integrante do sistema produtivo - aqui entendido em sentido amplo. Dessarte, o processo "produtivo" constitui-se pelo ataque e, subsequentemente, pelo saque das cidades derrotadas. Essa dinâmica é capitaneada pela elite aristocrática (aristoi), que controla todo o processo, em contraposição à

\footnotetext{
${ }_{7}^{6}$ Para uma análise breve da cena cf. THALMANN, 1988, p. 5-6.

7 Referem-se os autores a toda a história escrita. Cf. a nota de rodapé de F. Engels escrita a propósito da edição inglesa do Manifesto de 1888 e reproduzida na edição aqui utilizada.
} 
subordinada massa de soldados rasos (plêthus), de cujo produto da pilhagem as classes dominantes se apropriam da parte mais significativa. É essa apropriação do fruto do "trabalho" de uma maioria, efetuada por uma minoria hegemônica, que engendra a relação de exploração e, consequentemente, as classes e seu antagonismo.

Sainte Croix enuncia, entre as maneiras pelas quais uma classe se apropria do excedente produzido por outra, a exploração "mediante un sistema imperialista, explotando a otro país, es decir conquistándolo y sometiéndolo inmediatamente después al saqueo o bién imponiéndole un tributo" (1988, p. 71). Acrescentaríamos, pois, o segundo momento da apropriação, em que a elite composta pelos chefes dos oikos se apodera, durante a repartição do produto da rapina, da maior parte do saque conquistado pelo exército como um todo. Tratase, de fato, de uma cadeia de exploração, que começa nas vítimas da pilhagem, passa pelos soldados que empreendem o saque e, sobretudo, satisfaz a voracidade dos aristocratas em sua ânsia por ouro e escravos. Outrossim, não há, como observam Austin e Vidal-Naquet, nada de moralmente censurável nesse caráter teleologicamente econômico da guerra: "As razias organizadas com vistas à pilhagem não têm nada de excepcional, pelo contrário, e os heróis homéricos gabar-se-ão tranquilamente das suas proezas" (AUSTIN; VIDALNAQUET, 1986, p. 52).

Os mesmos autores, embora indiquem que: "O saque tomado ao inimigo será em seguida repartido pelos participantes na expedição, tendo o chefe direito a uma parte especial" (p. 52), não parecem considerar suficientemente a relevância da desproporcionalidade econômica da distribuição no que se refere ao quinhão da elite aristocrática frente ao contingente indistinto de soldados comuns - estes, obviamente, não desempenharão a liderança em quaisquer missões durante a contenda $e$, posto que constituam a gigantesca maioria do exército e arquem com o mais do ônus da guerra, contentar-se-ão com a menor parte dos bens saqueados - do que resulta a relação de exploração e, por conseguinte, de classes que sustentamos.

Efetivamente, não é contra essa expropriação do produto do butim, imposta aos soldados pelo comandante mor da armada, que se colocará Tersites em sua crítica a Agamémnon? 
"Filho de Atreu, estás descontente? Falta-te alguma coisa? As tuas tendas estão cheias de bronze e muitas mulheres escolhidas estão nas tuas tendas, essas que nós Aqueus te demos em primeiro lugar, quando saqueávamos uma cidade. Ou será ouro que tu queres? Ouro que te traga um dos Troianos domadores de cavalos de ílion, como resgate pelo filho, que eu ou outro dos Aqueus capturei e trouxe para cá? Ou será uma mulher jovem, para a ela te unires em amor, e para ficares só tu com ela? Parece mal ser quem manda neles a trazer as desgraças aos filhos dos Aqueus! Covardes! Tristes vergonhas! Mulheres aqueias, já não Aqueus! Regressemos para casa com as naus e deixemos aqui este homem em Troia para tirar proveito dos despojos, para que veja se nalguma coisa também nós contribuímos, ou não!

(Canto II, v. 225-238)

Sem embargo, a interpretação de Flores-Júnior - e de Kirk, a quem ele se refere - se encaminha de forma divergente. Com efeito, afirma o autor que a omissão de Homero quanto ao patronímico e ao lugar de origem de Tersites, única personagem da llíada acerca da qual nenhum dos dois nos é apresentado, tem sido comumente entendida como um indício de que o soldado seria não um nobre, mas alguém do plêthus - leitura de que compartilhamos. Todavia, na sequência, o autor afirma que:

Não é, no entanto, o que parece sugerir o próprio Tersites, ao afirmar que também ele trazia amarrados prisioneiros troianos cujo resgate beneficiava não a ele, mas a Agamêmnon, o que, no juízo de G. S. Kirk, indica sua participação no grupo dos guerreiros que combatiam na primeira linha, privilégio (ou dever) dos nobres (FLORES-JÚNIOR, 2010, p. 241).

Notoriamente, nossa interpretação e a de ambos os autores partem dos mesmos dados textuais para aportar em conclusões categoricamente adversas. A apreensão de bens e de cativos durante os ataques mais importantes não ficaria a cargo, como é evidente, de algumas dezenas, no máximo, de nobres comandantes, mas dos soldados como um todo. O cerne da questão aqui não é quem aprisiona, trata-se, contudo, de quem detém a posse do que é aprisionado.

A leitura que faz Postlethwaite do segmento narrativo dos versos 229 a $231^{8}$ também diverge bastante da que aqui apresentamos. Para ele:

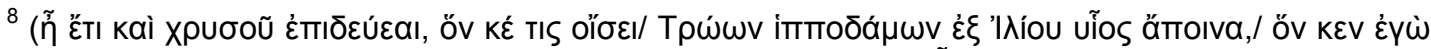

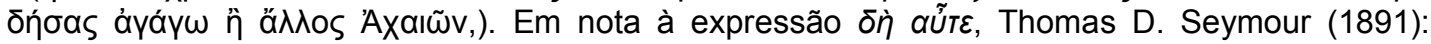
comenta que "Instead of inquiring the purpose of Agamemnon, Thersites attributes to the king the most selfish motives (implying that he continues the war only for his own private advantage), and alludes maliciously to the quarrel with Achilles.- "What dost thou lack? Hast thou not enough?"." 
The wording of this may well be intended to provoke mirth: 'or some other Achaian', added almost as an afterthought, throws the emphasis of the line back to the 'l', and heightens the air of pomposity. The idea of this misshapen individual providing Agamemnon with prisoners for ransom is more than a little ludicrous, as well as introducing an air of boastfulness. It may well be that Thersites intends to provoke merriment by his words: what we can be sure of is that his words are again echoing those of Achilleus during the quarrel. For Achilleus' case was two-fold: that Agamemnon receives the lion's share of the spoil, as was noted above, and that he, Achilleus, does the lion's share of the fighting (POSTLETHWAITE, 1988, p. 129).

A ideia de que a assertiva de Tersites encerra um tom jocoso parece, com efeito, contestável. Não se trata, em verdade, de uma afirmação imperativa - e não menos insolente e mesmo sarcástica - da dependência de Agamémnon em relação ao exército de aqueus como um todo? Não nos soa plausível pressupor que, por se tratar do "pior dos aqueus", um soldado comum não participaria, durante a tomada de uma cidade, de sua pilhagem subsequente e, desse modo, também do aprisionamento dos sobreviventes. Até porque, se Tersites não fosse capaz de desempenhar atividades ordinárias da práxis bélica, não haveria motivo para que estivesse entre os componentes da armada aqueia, tendo sobrevivido, ademais, até a reta final do conflito.

Outrossim, Flores-Júnior afirma que "poderíamos nos perguntar se Tersites teria voz na assembleia dos gregos se de fato fosse um guerreiro de baixa extração" (2010, p. 241). O argumento, mais uma vez, não nos parece convincente. Com efeito, poderíamos nos perguntar se Tersites "tem voz na assembleia", uma vez que seu discurso será punido violenta e exemplarmente por Ulisses. Ademais, ainda que considerássemos que o castigo decorre, não do fator de classe, mas do conteúdo do discurso - crítica virulenta contra o basileus basilei - poderíamos relembrar que, quando se trata, efetivamente, de um nobre (como no caso de Aquiles), independentemente da aspereza da fala, não há qualquer perspectiva de punição. A esse respeito, os apontamentos de Marcel Detienne se mostram bastante precisos:

(...) no grupo dos guerreiros profissionais, o discurso-diálogo, com suas características específicas, continua sendo um privilégio dos "melhores", dos áristoi do laós. A essa elite opõe-se a "massa", o dêmos, que designa a circunscrição territorial e depois o conjunto das pessoas que o habitam. (...) O homem do dêmos é Tersites, e a maneira como Ulisses o trata demarca os limites do discurso igualitário. Quando Tersites eleva 
a voz, Ulisses não procura convencê-lo com palavras, mas o abate com golpes do cetro. Tersites é o vil. Não tem direito de falar porque não é combatente. Para que Tersites participe do diálogo, para que a fronteira entre o laós e o dêmos se desvaneça, será necessária uma transformação importante: a extensão dos privilégios do guerreiro para todos os membros de um grupo social mais amplo. É a falange, a formação hoplita em que cada combatente ocupa um lugar na fileira, em que cada cidadão-soldado é concebido como unidade intercambiável, possibilitando a democratização da função bélica e, concomitantemente, a aquisição por um número maior de pessoas dos privilégios políticos até então reservados a uma aristocracia, a um grupo de "eleitos" (DETIENNE, 2013, p. 107).

E consoante com a leitura pautada pela questão de classe, afirma

Thalmann:

Both challenge the principle of "one ruler", but individual qualities aside, the reason why Achilles can make the challenge stick whereas Thersites is beaten into silence is their difference in class. After all, one cannot beat an Achilles, but one can find an outlet for this desire in Thersites (1988, p. 19).

Por outro lado, mostram-se pertinentes, ao nosso ver, os apontamentos de Postlethwaite acerca da caracterização de Tersites na Ilíada. Assim,

It would be difficult to imagine a figure more physically remote from the heroes he abuses. It may well be the case that Homer intended to portray Thersites as a figure of ridicule, or even to suggest failings of character through his ugliness; we can however be certain only of our observations, namely, that Thersites is everything a hero is not.

(...)

It may well be the case that Homer deliberately omitted Thersites' ancestry, and we may choose to speculate upon his possible motives for doing so; alternatively it has been argued that Homer did not inherit Thersites' ancestry through the oral tradition, and that information about him given by later authors was a fiction invented to fill the gaps which Homer left. Neither alternative may be proved, and again we may be certain only of what we may observe: that the absence of pedigree, just like his ugliness, serves to set Thersites quite apart from the heroes against whom he rails (POSTLETHWAITE, 1988, p. 125-6).

Como o autor pontua, as tradições alternativas, que relacionam Tersites a famílias e oikos aristocráticos, podem muito bem ser fruto de criações tardias - 0 que, na verdade, não temos como saber. Dessa forma, não nos parece seguro derivar uma hipótese de leitura do Tersites homérico de narrativas não homéricas. Por certo, o autor parte, assim como o presente trabalho, de uma leitura que se atém à construção da personagem no âmbito da llíada - postura 
diversa adotará Marks (2005), que relaciona o Tersites de Homero ao que se sabe sobre sua representação na Etiópida ${ }^{9}$.

A partir dessa leitura circunscrita àquilo que nos informa a llíada, forçoso é admitir com Postlethwaite "que Tersites é tudo o que um herói não é"; e sua caracterização não poderia estar mais distante daqueles contra os quais ele se coloca.

Sainte Croix identificará no Tersites homérico a figura do "agitador popular", que contesta a hierarquia de classes e a apropriação dos bens saqueados pelo comandante. Para o autor, esta personagem constitui o:

(...) retrato más antiguo que tenemos en griego, y tal vez en cualquier otra lengua, del "agitador" popular: se trata del de Tersites, que se atreve a hablar en contra del rey Agamenón en la asamblea del ejército griego que sitiaba Troya, tal como nos cuenta el libro II de la llíada (versos 211-278). Tersites está a favor de llevar anclas y volver a casa, dejando que Agamenón y sus nobles amigos descubran ellos solitos cuánto dependen, en realidad, de los soldados rasos; y se burla mucho de los grandes lotes de botín, em oro, bronce y mujeres, que el rey recibe de su hueste (1988, p. 481).

De fato, os versos que antecedem o discurso de Tersites, e que mostram Ulisses a admoestar os soldados, são bem explícitos no tocante à segmentação

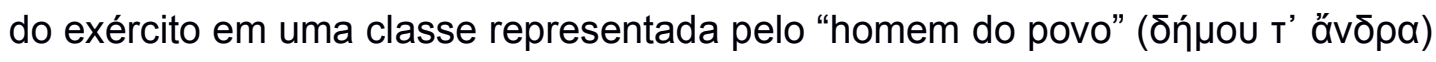

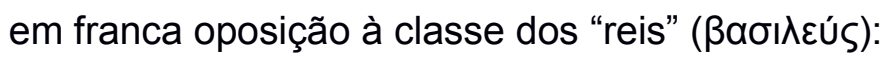

\footnotetext{
Mas se porventura via um homem do povo metido numa rixa, batia-lhe com o cetro, repreendendo-o com estas palavras: "Desvairado! Senta-te sossegado e ouve o que dizem outros, melhores que tu! Não passas de um covarde, de um fraco! Não serves para nada, nem na guerra, nem pelo conselho. Não penses que, aqui, nós Aqueus somos todos reis! Não é bom serem todos a mandar. É um que manda; um é o rei, a quem deu o Crônida de retorcidos conselhos o cetro e o direito de legislar, para que decida por todos." (Canto II, v. 198-206)
}

Há de se notar que, nos versos 198 e 199, o tratamento dispensado por Ulisses aos "homens do povo" não difere muito daquele destinado nos próximos

\footnotetext{
${ }^{9}$ Etiópida é um poema épico pertencente ao ciclo de narrativas relacionadas à Guerra de Tróia. $\mathrm{O}$ poema, perdido, teria sido escrito por Arctino de Mileto e narraria eventos imediatamente posteriores aos vistos na llíada. O conhecimento que possuímos da Etiópida, e de outras narrativas do Ciclo Troiano, se deve sobretudo à Crestomatia, de Proclo, que sintetiza, em linhas bastante gerais, o enredo do poema. Cf. GATTI, 2012.
} 
versos à figura de Tersites: a repreensão se dá por meio da violência física aliada à censura moral - ambas pautadas no reconhecimento impositivo da superioridade hierárquica de uma classe em relação à outra (v. 199-202). É o que explicita, de forma inequívoca, a assimetria com que Ulisses trata as distintas categorias de homens que encontra na cena.

A leitura que faz Thalmann (1988) dessa passagem também se coaduna com a ótica que adotamos, além de destacar o paralelismo na construção da passagem, elemento que parece acentuar sugestivamente a relação dicotômica:

\begin{abstract}
In speeches contrasted by a careful parallelism (lines 188-97, 198-206), Odysseus, in his treatment of those he encounters, discriminates according to class. He restrains "with gentle words" each "basileus and outstanding man he meets," saying, "friend, it is not fitting to intimidate you as though you were a coward [kakos]" (line 190). (...)

We learn more about that power in Odysseus' utterly different treatment

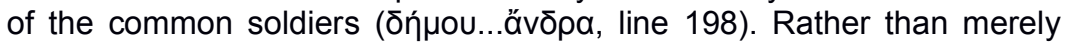
remind them of Agamemnon's possible anger, Odysseus acts directly himself as Agamemnon's substitute, using the royal sceptre to herd the soldiers back from the ships to the assembly if not actually bludgeoning them with it. As he does so, he gives a speech shot through with the ideology of class. The commoners should listen to others who are

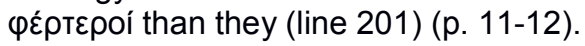

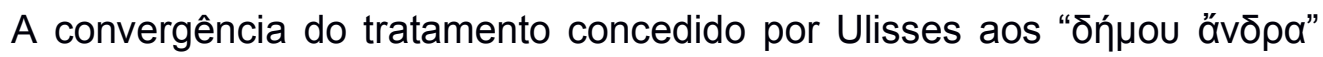
nessa passagem e ao "pior dos aqueus" no momento subsequente constitui, por certo, um indício importante que depõe a favor da compreensão do episódio de Tersites como um conflito entre classes sociais antagônicas. Enfim, acima de todos, o direito divino estabelece o basileus basileis, Agamémnon, cuja hegemonia, ideologicamente divina, assenta-se, todavia, sobre bases bastante materiais.

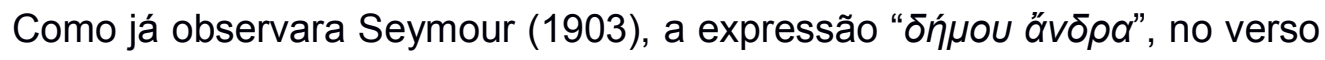

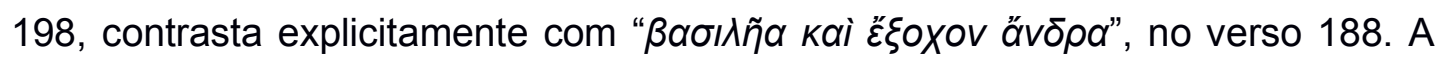
forma de admoestação dos reis e nobres por Odisseu - "Se porventura encontrava um rei ou outro homem nobre,/ aproximava-se dele e com palavras suaves o refreava" (v. 188-9) - é, expressamente, o antípoda das pancadas e humilhações destinadas aos soldados subalternos.

Em suas observações sobre a luta de classes na Antiguidade, abordando o plano ideológico, Sainte Croix pontua que: 
Una forma más retorcida de lucha ideológica de clases era el intento que hacián las clases dominantes de persuadir a aquellos a quienes explotaban a que aceptaran sin protestar su condición de oprimidos, e incluso, si ello era posible, a sentirse a gusto en ella. Según Aristóxeno de Tarento, discípulo de Aristóteles, la escuela pitagórica asentó el principio de que lo mismo que los governantes deben ser humanos, philanthrôpoi, así como versados en la ciencia del governar, también idealmente sus súbditos deberían no sólo obederceles, sino hallarlos de su agrado, ser philarchontes. Otra palabra interesante que no es nada rara es philodespotos, "amante del amo". En la época arcaica, el poeta aristocrático Teognis pensaba que tratando a patadas al "insensato dêmos" (la massa del pueblo) con la suficiente dureza, podría reducírsele a tan deseable condición (1988, p. 479).

A confluência entre o episódio homérico de Tersites e o discurso de Teógnis de Mégara (séc. VI AEC) parece-nos significativo. Essa continuidade discursiva ratifica, uma vez mais, a leitura da luta de classes ao referenciar historicamente a manutenção da oposição fundamental entre basileis/aristoi versus plêthus/demos no horizonte ideológico da elite grega antiga.

A despeito de não partir de uma abordagem propriamente marxista, VidalNaquet reconhecerá também, explicitamente, a caracterização do episódio de Tersites como um exemplo de "luta de classes":

No século $V$, os gregos utilizavam um termo para indicar a divisão no seio da cidade, a palavra stasis. Mas Homero não a conhece. Troia não é uma cidade dividida. E o campo aqueu, onde existem assembleias e conselhos, pode ser considerado uma "cidade" no sentido político do termo? A contestação aparece aí, de forma séria, uma só vez, para ser condenada sem demora.

(...) nesse canto II, que faz o catálogo dos guerreiros gregos e troianos, é um exemplo quase único de luta de classes. Ele investe contra Agamêmnon (...).

Tersites paga caro essa independência. Ulisses o golpeia, e todos se divertem (VIDAL-NAQUET, 2002, p. 44-5).

Ademais, o historiador francês parece indicar que o posicionamento ideológico por parte do poeta da llíada é bastante objetivo no tocante à sua apologia dos valores aristocráticos:

Homero chega a se referir aos simples soldados? Certamente que não (...). A única exceção é um homem cuja caricatura eu já lhes apresentei no capítulo 3: Tersites - o nome do seu pai não é citado, o que é um sinal característico. O poeta quis salvar do esquecimento o soldado raso Tersites? Ele é antes o eco, desfavorável, da existência, diante dos aristoi, de classes sociais menos gloriosas (VIDAL-NAQUET, 2002, p. 96-7). 
Nesse ponto, a leitura de Vidal-Naquet converge com a perspectiva de Sainte Croix, para quem Homero está, efetivamente, em franca oposição ideológica a Tersites. O britânico observa ainda que: “(...) la aristocrática sociedad para la que se componían los poemas homéricos habría encontrado perfectamente justo y adecuado el trato brutal que da Ulises a Tersites, considerándolo una acción propia de un gran hombre" (1988, p. 482). Essa tese, contudo, é colocada em xeque por Thalmann, para quem não se pode derivar de maneira simplista os posicionamentos ideológicos do poeta e do público a partir daqueles que se expressam no poema. Acertadamente, o autor assinala que "It is also undeniable, and important, that the result of the episode is the soldiers' enthusiasm for staying at Troy and continuing the war: authority and its accompanying ideology have been reinforced - for them" (1988, p. 2).

Por outro lado, Jim Marks (2005) contesta a abordagem do episódio homérico de Tersites enquanto conflito de classes. Para ele:

The "worst of the Achaians" is defined, by my interpretation, not in terms of social class but in terms of his relationship to the "anti-epic" genre of iambos, which was itself a vehicle for elite insider discourse. Thersites is the worst of the Achaians who count, which means he is the worst "basileus and man of standing." He is the scurrilous blame persona, who threatens to undermine heroic categories, but in the event helps to define them. He makes himself hateful to basileis and plêthus alike and thus helps maintain group integrity

(p. 27-28).

Há, entre os argumentos elencados pelo autor, vários apontamentos sólidos e admissíveis, a despeito de nossa discordância em relação ao todo de sua análise. Por outro lado, algumas de suas considerações não nos parecem assaz substantivas, ou mesmo plausíveis para sustentarem a refutação da hipótese da luta de classes. Com efeito, Marks afirma que:

(...) nowhere else in the lliad does a member of the plêthus speak in his own voice. Indeed, there are no other examples of overt class conflict in the poem or elsewhere in the corpus of early Greek epic. The absence of parallels does not prove that lliadic tradition could not include a named spokesman from and for the plêthus. It does foster the expectation that, if there is to be one programmatic representation of conflict between social classes in the Iliad, the relative status of the parties to the conflict would be made explicit (p. 2). 
Todavia, e como o próprio Marks forçosamente admite, o caráter sui generis do episódio de Tersites não constitui prova - ao nosso ver, tampouco indício - de que a personagem não representaria um "plebeu" confrontando a elite aristocrática. Ademais, soa-nos incerto balizar qualquer hipótese de leitura de uma tradição oral em critérios de representação programática de algo tão problemático quanto o conflito de classes.

Apesar de sua leitura contraposta à nossa ${ }^{10}$, o artigo de Jim Marks não desconsidera mecanicamente a questão do conflito de classes e, ainda que a discussão que propõe do tema paute-se pela refutação dela, ele reconhece explicitamente a importância dos elementos que a reiteram. Assim,

\begin{abstract}
These facts are of supreme importance to the class-conflict interpretation. Thersites' ugliness and near anonymity both distinguish him from the basileus class and establish his Homeric identity as the voice of the plêthus. As the old pun goes, "The peasants are revolting." Further, the emphasis on Thersites' negative attributes is meant not so much to undermine the purport of his speech (225-42), which echoes complaints already made by Achilleus, as to decry the fact that one of the plêthus dares to speak it. The equation of ugliness with low social rank is thus consistent with the poem's unmistakable sympathy for a rigid system of social ranking and for the group that occupies the top position in this system (MARKS, 2005, p. 4-5).
\end{abstract}

Além disso, Postlethwaite, contrapondo-se a uma certa leitura que toma a fala de Tersites como um eco paródico da fala de Aquiles no canto I, quando de seu embate com Agamémnon, afirma que:

If we may accept that Thersites' speech was not a coarse parody of Achilleus', but was intended rather as a re-hearsal of, and comment upon, the main theme of the poem, the quarrel and consequent menis, we may tentatively suggest that, having presented the 'heroic' attitude through the words of Nestor, Homer is now presenting the 'unheroic' attitude, the view of the ordinary soldiers at the other end of the heroic spectrum of the quarrel between their superiors and, above all, of the behaviour of their commander-in-chief, Agamemnon. According to this interpretation, the speech of Thersites would constitute an important element in Homer's presentation of the backcloth to the menis, namely, the psychology of the Achaian army, apart from the heroes, at Troy (POSTLETHWAITE, 1988, p. 133).

\footnotetext{
${ }^{10} \mathrm{O}$ ponto de vista defendido pelo autor não ignora a dimensão social da questão, no entanto, a aborda por um ponto de vista bastante distinto do nosso: "In other words, Thersites' revolting physique and detachment from family and homeland are unmistakable markers of his social function rather than of his social status" (MARKS, 2005, p. 5).
} 
Como o autor observa, o aguerrido discurso de Tersites contra Agamémnon é compreendido enquanto representação do ponto de vista dos soldados rasos - classe dominada - acerca do conflito centrado na cólera do comandante dos mirmidões. Diante da cisão no núcleo da classe dominante, concretizada na ruptura entre Aquiles e o basileus basilei, o conjunto de homens comuns que constitui o plêthus se posicionará em favor daquele, o que se explicita na convergência entre o discurso do "pior dos aqueus", na passagem analisada, e a célebre fala do filho de Tétis no canto I.

Parece-nos propício comentar agora um outro ponto difícil presente na passagem que ora analisamos. No segmento compreendido pelos versos 220 a 224, encontramos uma dificuldade expressa em identificar o referente anaforicamente recuperado pelo pronome Tữ no verso 222; trata-se efetivamente de Tersites ou de Agamémnon?

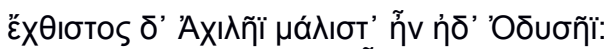

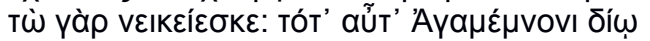

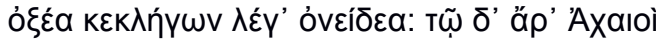

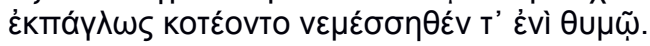

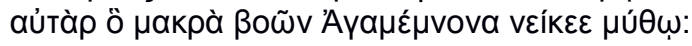
(v. 220-224)

A leitura de Flores-Júnior, apoiado em Postlethwaite, parece-nos, sobremaneira, correta:

Toda dificuldade reside em saber a quem se refere o pronome $T \tilde{\omega}$ no verso 222: a Agamêmnon ou a Tersites? Kirk, considerando excessivamente violentas as palavras em 223, opta pelo segundo. Contrária é a posição de N. Postlethwaite, que julga, ao contrário, bastante razoável que os aqueus estivessem fortemente agastados com seu comandante, após todos os anos de guerra e num momento em que o rumo das coisas parecia incerto como jamais. Parece-me a melhor leitura. De acordo com ela, a simetria dos dativos $\theta u \mu \tilde{\omega}$ e $\mu u ́ \theta \omega$ no fim dos versos 223 e 224 respectivamente ilumina a intervenção de Tersites (FLORES-JÚNIOR, 2010, p. 247).

Tanto elementos textuais quanto narrativos parecem corroborar essa interpretação. Postlethwaite, nesse sentido, observa que:

We are surely justified in dismissing Kirk's argument that 'the violence of the language is excessive for what they might have felt for their commanding general': in view of the fact that they have endured over nine years of warfare with, long still to go, and have just been the chance to return home, only words 'he was just testing you', the strength of 
feeling amongst the Achaians. (...) the Achaians feel the anger in their hearts, but Thersites actually expresses it in his words. In this case the object of the anger, of both Thersites and of the Achaian army in general, is Agamemnon (POSTLETHWAITE, 1988, p. 134-5).

Por fim, a atribuição do tụ a Tersites parece implicar outra dificuldade, a saber, como justificar que os soldados aqueus riam prazenteiramente do castigo imputado por Odisseu a Tersites, se este tão somente dá voz a um sentimento compartilhado por eles mesmos? Vejamos o excerto que corresponde à tradução dos versos 270 a 275 :

\begin{abstract}
Mas os outros, embora acabrunhados, riam-se aprazivelmente. Entre eles um assim dizia, olhando de soslaio para outro: "Ah, na verdade são aos milhares os feitos valentes de Ulisses, tanto na primazia dos conselhos como na autoridade guerreira! Mas esta foi a melhor coisa que ele fez entre os Argivos, visto que cortou o palavreado a este caluniador desavergonhado.
\end{abstract}

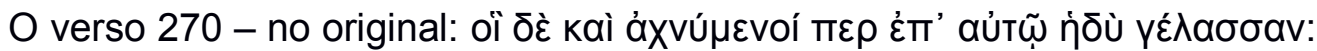
- explicita a dissonância entre o sentimento dos aqueus e sua reação à atitude de Odisseu. Esse descompasso é indicado pelo caráter concessivo do particípio

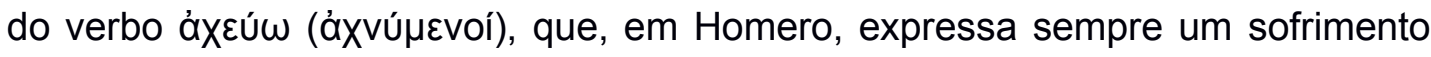
não físico, uma angústia do espírito. Assim, é a despeito da aflição - do ressentimento, verterá Haroldo de Campos - que sentem, que os soldados riem da agressão de Odisseu destinada a Tersites. Em conformidade com a leitura pautada pelo conflito de classes aqui proposta, talvez possamos compreender o riso e a aprovação dos soldados em relação à ação do rei de Ítaca como, por um lado, uma distensão, uma válvula de escape, para todo o crescente descontentamento e frustração que, nesse momento, parece dominá-los e, por outro, como uma sujeição, socialmente imposta, a um representante da classe dominante. Com efeito, a leitura que Thalmann faz da cena se mostra convergente com essa perspectiva:

The soldiers' hopes of return home have been aroused and then frustrated, and they have been herded back in a humiliating way that stresses their subservience. This resentment would naturally be focused on Agamemnon as their commander-in-chief. Thersites' punishment discharges the tension (...) (1988, p. 18) 
Revista Investigações Vol. 31, nº l, Junho/2018

Se considerarmos a etimologia do nome Tersites - vinculada à ideia de "coragem para fazer alguma coisa, coragem contra alguma coisa ou alguém"11 -, podemos facilmente considerar que, assistindo ao seu "porta-voz" ser tão violentamente reprimido por ousar dar vazão à insatisfação do exército para com o atrida que os comanda, a massa de homens comuns que constitui a armada percebe concretamente que a todo e qualquer transgressor da ordem social estabelecida sobrevirão sanções exemplares. Se àquele que é denominado pela coragem de se rebelar uma paga tão desgostosa se destina, ao contingente anônimo dos subordinados resta a resignação. Manda quem pode, obedece quem tem juízo.

\section{Referências}

AUSTIN, Michel; VIDAL-NAQUET, Pierre. O mundo homérico. In: Economia e sociedade na grécia antiga. Lisboa: Edições 70, 1986.

CARDOSO, Ciro Flamarion. Sete olhares sobre a Antiguidade. Brasília: Editora Universidade de Brasília, 1998.

DETIENNE, Marcel. Mestres da verdade na Grécia Arcaica. Trad. Ivone C. Benedetti. São Paulo: Editora WMF Martins Fontes, 2013.

Eduardo Galeano: wars lie... Trecho de entrevista com Eduardo Galeano. 2015. (2'57"). Disponível em: < https://www.youtube.com/watch?v=sunZmneQzQE\&t=1s >. Acesso em: $10 \mathrm{de}$ maio de 2018.

DONLAN, Walter. Kin-Groups in the Homeric Epics. Classical World, Volume 101, $\mathrm{n}^{\circ}$ 1, 2007, p. 29-39. Baltimore (USA): Johns Hopkins University Press.

FLORES-JÚNIOR, Olimar. Cinismo e retórica: o caso Tersites. In: ASSUNÇÃO, Teodoro Rennó; FLORES-JÚNIOR, Olimar; MARTINHO, Marcos. (Org.) Ensaios de retórica antiga. Belo Horizonte: Tessitura, 2010. 11 Indicada por Flores-Júnior (2010, p. 238-ss.); cf. a passagem para uma etimologia mais
detalhada do nome Tersites. 
GATTI, Ícaro Francesconi. A Crestomatia de Proclo: tradução integral, notas e estudo da composição do códice 239 da Biblioteca de Fócio. 2012. Dissertação (mestrado em Letras Clássicas) - Faculdade de Filosofia, Letras e Ciências Humanas da Universidade de São Paulo. São Paulo.

HOBSBAWM, E. J. Class consciousness in history. In: MÉSZAROS, István (ed.). Aspects of history and class consciousness. Londres: Routledge \& Kegan Paul, 1971.

HOMERO; SEYMOUR, Thomas D. The first three books of Homer's lliad. Introduction, commentary, and vocabulary: Thomas D. Seymour. Boston: Ginn and Company, 1903. Disponível em: < https://archive.org/details/firstthreebooks02homegoog>. Acesso em: 15 de maio 2018.

HOMER. Homeri Opera in five volumes. Oxford, Oxford University Press. 1920. Disponível em: <http://www.perseus.tufts.edu/hopper/text?doc=Perseus\%3atext\%3a1999.01.013 3>. Acesso em: 15 ago. 2018.

HOMERO. Ilíada. Tradução e prefácio de Frederico Lourenço. Introdução e apêndices: Peter Jones. Introdução à edição de 1950: E. V. Rieu. São Paulo: Penguin; Companhia das Letras, 2013.

LENIN, V. I. As tarefas das uniões da juventude. In: . Obras escolhidas. São Paulo: Editora Alfa-Omega, 1980. t. 3, p. 386-397.

LUCÁKS, Georg. História e consciência de classe: estudos sobre a dialética marxista. São Paulo: Martins Fontes, 2003.

MARKS, Jim. The ongoing neikos: Thersites, Odysseus, and Achilleus. American Journal of Philology, 126, p. 1-31, 2005. Baltimore (USA): The Johns Hopkins University Press.

MARX, Karl; ENGELS, Frederich. A ideologia alemã. Supervisão ed. Leandro Konder. Trad. Rubens Enderle, Nélio Schneider e Luciano C. Martorano. São Paulo: Boitempo, 2007.

- Manifesto Comunista. Organização e introdução: Osvaldo Coggiola. Trad. Álvaro Pina. São Paulo: Boitempo, 2005.

OSBORNE, Robin. Homer's Society. In: FOWLER, Robert (editor). THE CAMBRIDGE COMPANION TO HOMER. Cambridge: Cambridge University Press, 2006. 
PAULO NETTO, J. Introdução ao estudo do método de Marx. São Paulo: Expressão Popular, 2011.

POSTLETHWAITE, N. Thersites in the 'Iliad'. Greece \& Rome, 35, n² 2, p. $123-$ 136, out. 1998. Cambridge University Press.

SAINTE CROIX, Geoffrey Ernest Maurice de. La lucha de clases en el mundo griego antiguo. Trad. Teófilo de Lozoya. Barcelona: Editorial Crítica, 1988.

THALMANN, W. G. Thersites: comedy, scapegoats, and heroic ideology in the Iliad. Transactions of the American Philological Association, Volume 118, 1988, p. 1-28. Baltimore (USA): Johns Hopkins University Press.

VIDAL-NAQUET, Pierre. O mundo de Homero. Trad. Jônatas Batista Neto. São Paulo: Companhia das Letras, 2002.

Recebido em 20/08/2018.

Aprovado em 20/10/2018. 